\title{
Immunoexpression of Trefoil Factor 1 in Non-Neoplastic and Neoplastic Canine Gastric Tissues
}

\author{
Ana R. Flores ${ }^{1,2,3}$, Marisa Castro ${ }^{1}$, Alexandra Rêma ${ }^{1}$, João R. Mesquita ${ }^{4} \mathbb{D}$, Marian Taulescu ${ }^{5,6, *(\mathbb{D} \text {, }}$ \\ Fátima Gärtner 1,2,7 (D), Fernanda Seixas ${ }^{3}$ (D) and Irina Amorim 1,2,7 (i)
}

1 Department of Pathology and Molecular Immunology of the Institute of Biomedical Sciences Abel Salazar (ICBAS), University of Porto, 4050-313 Porto, Portugal; anaruteflores@gmail.com (A.R.F.); mmcastro@icbas.up.pt (M.C.); alexandra.rema@gmail.com (A.R.); fgartner@ipatimup.pt (F.G.); iamorim@ipatimup.pt (I.A.)

2 Institute of Pathology and Molecular Immunology of the University of Porto (IPATIMUP), 4200-465 Porto, Portugal

3 Animal and Veterinary Research Center (CECAV), Associate Laboratory AL4AnimalS, University of Trás-os-Montes e Alto Douro (UTAD), 5001-801 Vila Real, Portugal; fseixas@utad.pt

4 Epidemiology Research Unit (EPIUnit), Instituto de Saúde Pública da Universidade do Porto (ISPUP), 4050-600 Porto, Portugal; jmesquita@outlook.com

5 Department of Pathology, Faculty of Veterinary Medicine, University of Agricultural Sciences and Veterinary Medicine, 400372 Cluj-Napoca, Romania

6 Synevovet Laboratory, 81 Pache Protopopescu, 021408 Bucharest, Romania

7 i3S-Instituto de Investigação e Inovação em Saúde, Universidade do Porto, 4200-135 Porto, Portugal

* Correspondence: marian.taulescu@usamvcluj.ro

check for updates

Citation: Flores, A.R.; Castro, M.; Rêma, A.; Mesquita, J.R.; Taulescu, M.; Gärtner, F.; Seixas, F.; Amorim, I. Immunoexpression of Trefoil Factor 1 in Non-Neoplastic and Neoplastic Canine Gastric Tissues. Animals 2021, 11, 2855. https://doi.org/10.3390/ ani11102855

Academic Editor: Emir Hadzijusufovic

Received: 18 August 2021

Accepted: 26 September 2021

Published: 29 September 2021

Publisher's Note: MDPI stays neutral with regard to jurisdictional claims in published maps and institutional affiliations.

Copyright: (c) 2021 by the authors. Licensee MDPI, Basel, Switzerland. This article is an open access article distributed under the terms and conditions of the Creative Commons Attribution (CC BY) license (https:// creativecommons.org/licenses/by/ $4.0 /)$.
Simple Summary: Gastric carcinoma (GC) is the second leading cause of death in humans and the most frequent malignancy in the stomach of dogs. As in humans, the prognosis of canine gastric cancer is generally poor owing to the advanced stage at the time of diagnosis, resulting in limited treatment options. In dogs, the molecular mechanisms involved in the growth and progression of gastric cancer remain largely unknown. Trefoil factor 1 (TFF1) protein is a mucin-associated secretory molecule that plays an important role in the maintenance and protection of epithelial surface integrity. Some human studies showed that TFF1 can protect mucosa against damage and suppress carcinogenesis, while other studies showed that TFF1 can restrict cell adhesion, promote tumor cell invasion, and block necrosis of tumor cells. In human gastric cancer, TFF1 has been found to decrease, and it has been proposed that it might act as a tumor suppressor factor. The present study was carried out to investigate whether there is a relationship between TFF1 and canine gastric carcinogenesis. We found an association between reduced expression of TFF1 and the development and progression of gastric cancer in dogs. The pathological and behavioral similarities between spontaneous canine GC and human counterparts make it logical to assume that dogs may be a useful model for human gastric cancer.

Abstract: TFF1 expression is markedly reduced in human GCs, suggesting that TFF1 is a tumor suppressor for human gastric cancer. The present study evaluated the expression and distribution pattern of TFF1 in paraffin-embedded canine gastric tissue samples, including normal mucosa $(\mathrm{n}=3)$, polyps $(\mathrm{n}=8)$, carcinomas $(\mathrm{n}=31)$ and their adjacent non-neoplastic mucosa $(\mathrm{n}=30)$, neoplastic emboli $(n=14)$, and metastatic lesions $(n=9)$, by immunohistochemistry (IHC). All normal gastric tissues expressed TFF1 in the superficial foveolar epithelium and mucopeptic cells of the neck region. Most gastric polyps (GPs) displayed immunoreactivity for TFF1 in $>75 \%$ of the epithelial component. In GCs, the expression of TFF1 was found reduced in $74.2 \%$ of the cases. The level of TFF1 expression had a decreased tendency from normal gastric mucosa to GPs and GCs $(p<0.05)$. No significant differences in the expression of TFF1 were found in GCs, according to age, sex, histological type based on World Health Organization (WHO) and Lauren classification, tumor location, depth of tumor invasion, presence of neoplastic emboli or metastatic lesions. The median survival time of GC patients with preserved and reduced TFF1 immunoexpression were 30 and 12 days, respectively. Kaplan-Meier analysis revealed no significant survival differences between 
the two groups $(p>0.05)$. These findings suggest that TFF1 protein may play a role in canine gastric carcinogenesis, and further studies are necessary to define its usefulness as a prognostic indicator in canine gastric carcinoma.

Keywords: dog; gastric carcinoma; gastric polyps; trefoil factor 1; stomach

\section{Introduction}

Gastric carcinoma is the most frequent malignant neoplasm of the stomach in dogs, comprising $50-90 \%$ of all canine gastric malignancies, and usually results in death. Although, in recent years this canine disease appears to have been diagnosed more frequently, prognosis is generally poor owing to the advanced stage at the time of diagnosis, resulting in limited treatment options [1]. Treatment involves surgical resection that is often complicated by diffuse infiltration, metastasis, and a frequently debilitated patient [1-3].

The WHO for domestic animals subdivided GCs into papillary, tubular, mucinous, signet ring cell, and undifferentiated types [4]; however, previous studies demonstrated that some canine gastric neoplastic lesions fit specific histological types only described in the human WHO classification, such as poorly cohesive and mixed carcinomas $[1,5]$. Despite its usefulness in the recognition of the morphological patterns, WHO classification schemes offer little prognostic significance [4,6]. In turn, the human Lauren classification may more accurately predict prognosis based on histopathological features and has been successfully adapted to the $\operatorname{dog}[7-10]$.

In humans, studies emphasize that GPs may be intermediate steps in the process of malignant transformation leading to specific histological types of GC [11,12]. According to the current veterinary literature, there are no validated pre-neoplastic lesions of GC, although atrophic gastritis, a type of giant hypertrophic gastropathy or Ménétrier's disease, and intestinal metaplasia (IM) have been recognized in dogs and associated with possible predisposition to gastric cancer development [2,13-15]. As in humans, GPs are incidental findings in dogs; however, previous studies conducted by our group suggest that canine GPs are proliferative and hyperplastic lesions with lack of features suggestive of neoplastic transformation $[10,16]$.

Trefoil factor peptides (TFFs) are a family of mucin-associated secretory molecules that have an important role in the maintenance and protection of epithelial surface integrity [17]. They are secreted in response to injuries, acting as mitogens to facilitate cell migration into the lesion, forming a protective barrier, and thus being crucial for epithelial restitution, particularly of mucosal surfaces. In addition, TFFs have been described as potent inhibitors of apoptosis and anoikis (cell death induced by anchorage independence) [18].

In mammals, the TFF family consists of three members: TFF1 (previously pS2), TFF2 (formerly spasmolytic polypeptide or SP), and TFF3 (or intestinal trefoil factor). TFF peptides possess a sequence of about 40 amino acids termed TFF domain (formerly: P-domain, trefoil domain) that contains six conserved cysteine residues with three intramolecular disulfide bonds (Cys ${ }^{\mathrm{I}-\mathrm{V}}$, Cys ${ }^{\mathrm{II}-\mathrm{IV}}$, and Cys $\left.{ }^{\mathrm{III}-\mathrm{VI}}\right)$. Both, TFF1 and TFF3 have one trefoil domain, while TFF2 has two trefoil domains [17].

Trefoil factor 1, a $6.7 \mathrm{kDa}$ protein of 60 amino acids, was originally isolated from estrogen-induced human breast cancer cell line MCF-7 [19,20] and is normally expressed in the superficial and foveolar epithelium of the gastric mucosa and in the upper ducts of Brunner's glands in the duodenum in both rodents and humans [21,22]. Additionally, TFF1 was also detected in the gastric juice [17].

In recent years, clinical and experimental studies have shown an active function of the TFF1 in the oncogenic transformation, growth, and metastatic extension of common human solid tumors, including breast, pancreas, colon, and stomach cancer [23]. Animal experiments showed that TFF1 knockout mice develop marked hyperplasia and dysplasia of gastric cells, antral/pylorus-specific adenoma and, in 30\% of cases, multifocal intraep- 
ithelial or intramucosal carcinoma [24]. In human gastric tissues, the expression of TFF1 has been found decreased in IM and adenomas compared with adjacent normal mucosa, and completely lost in about $40 \%$ to $60 \%$ of the carcinomas [12,25-27]. Thus, it has been proposed that TFF1 functions as a gastric tumor suppressor gene [28].

The genes encoding TFFs were previously characterized in dogs and cats [29]. Schmitz et al. [30] assessed TFF gene expression in the gastrointestinal tract from dogs with inflammatory bowel disease (IBD) by PCR and demonstrated that TFF1 expression was significantly upregulated in duodenum of dogs with inflammatory bowel disease (IBD). Very little is known regarding TFF1 in canine gastric tissues.

The aims of the present study were: (1) to evaluate the expression and distribution pattern of TFF1 in normal gastric mucosa, GPs, and malignant gastric tumors with neoplastic emboli and corresponding metastasis in dogs; (2) to determine whether there was an association between the expression of this protein and clinicopathological features of the tumors and patient's survival time.

\section{Materials and Methods}

\subsection{Ethics Statement}

All the examined samples were collected for diagnostic purposes as part of routine standard care based on the best clinical judgement of their attending practitioners, and the investigators had no influence on the execution of any clinical procedures. Owners gave informed consent to use clinical data and the excised tissues for teaching and research purposes. The study was approved by Animal Welfare Organization (ORBEA) of the ICBAS-UP (Porto, Portugal), authorization N 201/2017.

\subsection{Sample Collection}

Thirty-nine canine gastric lesions, obtained during endoscopic procedures, surgery, or necropsy examination between 2004 and 2021, were selected from the archives of the Laboratory of Veterinary Pathology, ICBAS-UP (Porto, Portugal). These included 8 GPs and 31 GCs. Regarding GCs, full-thickness biopsies were performed in 22 cases (71\%); partial biopsies including mucosa, submucosa, and tunica muscularis were achieved in 6 cases $(19.4 \%)$; in the remaining 3 cases, partial biopsies were performed, which included the mucosal and submucosal layers $(9.7 \%)$. Samples of normal canine body and antral gastric mucosa were collected during necropsy examination of three animals that died of causes not related with gastrointestinal diseases.

Epidemiological and clinical data of the dogs diagnosed with gastric disease was collected from the histopathological request forms (Table 1). When available, medical records were also reviewed to obtain the outcome of gastric cancer patients.

\subsection{Histological Evaluation}

Tissues were fixed in 10\% buffered formalin and paraffin embedded. Serial consecutive $2 \mu \mathrm{m}$-thick sections were made; one being stained with Hematoxylin and Eosin (H\&E, Merck, Darmstadt, Germany) for histological diagnosis and the other for the immunohistochemical study.

All sections, including normal gastric samples, GPs, and GCs were independently examined by three veterinary pathologists. When there was a disagreement, a consensual diagnosis was achieved through simultaneous observation using a multi-head microscope. If this approach was not possible for some reason, and since the slides of all cases were scanned, pathologists reached consensus through their joint, but at a distance, virtual reassessment.

Normal gastric tissues were considered as such according to the previously proposed criteria [33] and were negative for the presence of Helicobacter spp. (confirmed by modified Giemsa stain and IHC using anti-H. pylori polyclonal antibody (RBK012; Zytomed, Berlin, Germany, diluted 1:200)). 
Table 1. Animal epidemiological data (breed, age, sex) and characteristics of the specimens included in the present study.

\begin{tabular}{|c|c|c|c|c|c|}
\hline Case & Breed & $\begin{array}{l}\text { Sex/Age } \\
\text { (Years) }\end{array}$ & $\begin{array}{l}\text { Location of } \\
\text { the Lesion }\end{array}$ & \multicolumn{2}{|c|}{ Histological Diagnosis } \\
\hline 1 & Boxer & $\mathrm{M} / 10$ & $\mathrm{~N} / \mathrm{A}$ & \multicolumn{2}{|c|}{ Normal mucosa } \\
\hline 2 & Basset hound & $\mathrm{F} / 9$ & $\mathrm{~N} / \mathrm{A}$ & \multicolumn{2}{|c|}{ Normal mucosa } \\
\hline 3 & Yorkshire terrier & $\mathrm{M} / 3$ & $\mathrm{~N} / \mathrm{A}$ & \multicolumn{2}{|c|}{ Normal mucosa } \\
\hline 4 & Crossbreed & $\mathrm{M} / 16$ & Body & \multicolumn{2}{|c|}{ Inflammatory polyp } \\
\hline 5 & Poodle & $\mathrm{M} / 12$ & Antrum & \multicolumn{2}{|c|}{ Hyperplastic polyp } \\
\hline 6 & Boxer & $\mathrm{M} / 10$ & Antrum & \multicolumn{2}{|c|}{ Hyperplastic polyp } \\
\hline 7 & German shepherd & $\mathrm{M} / 9$ & Antrum & \multicolumn{2}{|c|}{ Inflammatory polyp } \\
\hline 8 & Irish setter & $\mathrm{F} / 12$ & Antrum & \multicolumn{2}{|c|}{ Hyperplastic polyp } \\
\hline 9 & Argentine mastiff & $\mathrm{F} / 9$ & Antrum & \multicolumn{2}{|c|}{ Hyperplastic polyp } \\
\hline 10 & Poodle & $\mathrm{M} / 13$ & Antrum & \multicolumn{2}{|c|}{ Inflammatory polyp } \\
\hline 11 & Crossbreed & $\mathrm{F} / 16$ & Antrum & \multicolumn{2}{|c|}{ Hyperplastic polyp } \\
\hline & & & & WHO [31] & Lauren [32] \\
\hline 12 & Basset hound & $\mathrm{F} / 12$ & Antrum & Tubular & Intestinal \\
\hline 13 & Cocker spaniel & $\mathrm{M} / 13$ & Antrum & Signet ring cell & Diffuse \\
\hline 14 & Chow-chow & $\mathrm{F} / 11$ & Antrum & Mixed & Indeterminate \\
\hline 15 & Shih Tzu & $\mathrm{F} / 10$ & Antrum & Poorly cohesive & Diffuse \\
\hline 16 & Chow-chow & $\mathrm{M} / 10$ & Antrum & Signet ring cell & Diffuse \\
\hline 17 & English bulldog & $\mathrm{M} / 6$ & Body & Signet ring cell & Diffuse \\
\hline 18 & Labrador retriever & $\mathrm{F} / 14$ & Body & Tubular & Intestinal \\
\hline 19 & Shar-pei & $\mathrm{M} / 5$ & Body & Signet ring cell & Diffuse \\
\hline 20 & Belgian shepherd & $\mathrm{F} / 11$ & Body & Mixed & Indeterminate \\
\hline 21 & Golden retriever & $\mathrm{M} / 14$ & Body & Signet ring cell & Diffuse \\
\hline 22 & Labrador retriever & $\mathrm{M} / 8$ & Antrum & Mixed & Indeterminate \\
\hline 23 & Siberian husky & $\mathrm{F} / 12$ & Antrum & Tubular & Intestinal \\
\hline 24 & Crossbreed & $\mathrm{M} / 10$ & Body & Mucinous & Diffuse \\
\hline 25 & Crossbreed & $\mathrm{F} / 8$ & Body & Poorly cohesive & Diffuse \\
\hline 26 & Siberian husky & $\mathrm{M} / 13$ & Antrum & Tubular & Intestinal \\
\hline 27 & $\begin{array}{c}\text { Crossbreed (X German } \\
\text { shepherd) }\end{array}$ & $\mathrm{F} / 13$ & Body & Poorly cohesive & Diffuse \\
\hline 28 & Akita & $\mathrm{M} / 9$ & Body & Poorly cohesive & Diffuse \\
\hline 29 & Collie & $\mathrm{M} / 11$ & Body & Mixed & Indeterminate \\
\hline 30 & Alaska malamute & $\mathrm{M} / 6$ & ID & Signet ring cell & Diffuse \\
\hline 31 & Golden retriever & $\mathrm{M} / 10$ & Antrum & Signet ring cell & Diffuse \\
\hline 32 & Chow-chow & $\mathrm{M} / 9$ & Antrum & Poorly cohesive & Diffuse \\
\hline 33 & Pointer & $\mathrm{M} / 11$ & Body & Signet ring cell & Diffuse \\
\hline 34 & Collie & $\mathrm{M} / 11$ & $\begin{array}{l}\text { Body and } \\
\text { antrum }\end{array}$ & Poorly cohesive & Diffuse \\
\hline 35 & Boxer & $\mathrm{M} / 7$ & Antrum & Signet ring cell & Diffuse \\
\hline 36 & Crossbreed & $\mathrm{F} / 7$ & Antrum & Poorly cohesive & Diffuse \\
\hline 37 & Chow-chow & $\mathrm{M} / 6$ & Body & Mucinous & Diffuse \\
\hline 38 & $\begin{array}{l}\text { West highland white } \\
\text { terrier }\end{array}$ & $\mathrm{F} / 13$ & Antrum & Signet ring cell & Diffuse \\
\hline 39 & Standard Poodle & $\mathrm{M} / 8$ & Antrum & Mixed & Indeterminate \\
\hline 40 & Crossbreed (X Poodle) & $\mathrm{F} / 9$ & Antrum & Papillary & Intestinal \\
\hline 41 & Miniature Poodle & $\mathrm{F} / 14$ & Antrum & Tubular & Intestinal \\
\hline 42 & German shepherd & $\mathrm{M} / 12$ & $\begin{array}{l}\text { Body and } \\
\text { antrum }\end{array}$ & Poorly cohesive & Diffuse \\
\hline
\end{tabular}

M-male, F-female; N/A-not applicable; ID—data was not available.

Gastric polyps were classified according to WHO classification for domestic animals' diagnostic criteria [4].

GC cases were reclassified according to the diagnostic criteria of the human WHO (2010) [31] since WHO classification of digestive system tumors for domestic animals does not include all the histological subtypes recognized in this study. Canine GCs were classified as tubular when they contained prominent neoplastic tubules; as papillary when neoplastic cells formed papillary structures; mucinous when they contained $>50 \%$ of extracellular mucin and signet ring cell and when the great majority of the tumor was composed of malignant cells containing intracytoplasmic mucin vacuoles and eccentric nuclei. Additionally, two other neoplastic malignant entities were considered: poorly cohesive carcinomas when lesions were mainly composed of poorly cohesive cells, morphologically 
resembling histiocytes, lymphocytes and plasma cells; and mixed carcinomas when they contained a mixture of well differentiated and signet ring/poorly cohesive histological components $[1,31]$. Tumors were further classified according to Lauren classification into the following categories: intestinal type when they contained rudimentary glands that superficially resembled intestinal glands; diffuse type when they contained cells that failed to form distinct structures; indeterminate type when they contained equal proportions of intestinal and diffuse characteristics [32]. For statistical purposes, tumors were divided into two main histological subgroups: differentiated type consisting of papillary and tubular carcinomas, and poorly/undifferentiated type consisting of mucinous, signet ring cell, poorly cohesive, and mixed carcinomas. The anatomic location was determined by combining the clinical information and imaging exams provided by the assistant veterinarian with the analysis of the gastric tissue fragments sent for histopathological analysis, which in most cases allowed the confirmation of the gastric region affected. The depth of tumor invasion of the gastric wall was recorded in every case as the deepest layer invaded: mucosa, submucosa, tunica muscularis, and serosa. However, for statistical analysis only cases that included all layers of the gastric wall (full-thickness biopsies) were considered.

\subsection{Immunohistochemistry}

For IHC, sections were deparaffinized, hydrated, and antigen retrieval was performed in a water bath in 10\% citrate buffer, $\mathrm{pH}$ 6, for $20 \mathrm{~min}$. The NovolinkTM Max-Polymer detection system (Novocastra, Newcastle, UK) was used for visualization, according to the manufacturer's instructions. Slides were incubated with anti-estrogen inducible protein pS2 rabbit monoclonal antibody (clone EPR3972, ab92377, Abcam, Cambridge, UK), diluted 1:2000, overnight at $4{ }^{\circ} \mathrm{C}$ in a humid chamber. Sections were rinsed with triphosphate buffered saline (TBS, Cell marque, Merck, Darmstadt, Germany) in each step of the procedure. Color was developed with 3.3- diamino-benzidine (DAB; Sigma, St. Louis, MO, USA) and sections were then counterstained with hematoxylin, dehydrated, and mounted. Positive control tissues were represented by sections of human gastric mucosa with IM, obtained from the pathology department archive of Hospital Santo Antonio (Porto, Portugal), known to express TFF1. Negative controls were performed by replacing the primary antibody by an antibody of the same immunoglobulin isotype at the same concentration as the former.

All immunostained slides were independently evaluated by three observers in blind testing - without the knowledge of the specific diagnosis or prognosis for each individual case. When there was a disagreement, a consensual diagnosis was achieved through simultaneous observation using a multi-head microscope. In normal canine gastric mucosa, the TFF1 immunolabeling was evaluated at the superficial foveolar epithelium and glandular structures of both body and antral gastric regions. In GPs, TFF1 immunoexpression was evaluated in all epithelial components. In GCs, the TFF1 immunoreactivity was evaluated in both neoplastic epithelial cells and in non-neoplastic gastric mucosa adjacent to carcinomas.

TFF1 immunoreactivity was scored semi-quantitatively according to the presence of immunoreactive cells as: - , none or rare positive cells $(<5 \%) ;+, 5-25 \% ;++, 25-75 \%$; +++ , $>75 \%$ [34]. The subcellular location of the immunostaining was classified as cytoplasmic (diffuse or apical) or membranous. For further statistical analysis, TFF1 immunoexpression was grouped into preserved $(+++)$ or reduced $(-,+,++)$, in comparison with the immunoreactivity observed in normal canine gastric mucosa.

\subsection{Protein Extraction and Western Blotting}

To validate the specificity and cross-reactivity of this specific antibody with canine tissues, a Western blot analysis was performed in a sample of normal canine gastric mucosa. Briefly, the proteins were extracted from the formalin-fixed and paraffin-embedded tissues (FFPE) using the Qproteome FFPE tissue kit (Qiagen, Germantown, MD, USA). The amount of protein in each extract was estimated with Pierce ${ }^{\circledR}$ BCA Protein Assay Kit (Thermoscientific, Rockford, IL, USA) and $20 \mu \mathrm{g}$ of protein were separated in $8 \%$ acrylamide/bis 
acrylamide (Sigma, St. Louis, MO, USA) SDS-PAGE gel. The gel was transferred onto a nitrocellulose membrane, blocked with $5 \%$ skim milk for $1 \mathrm{~h}$ at room temperature, and incubated with anti-estrogen inducible protein pS2 rabbit monoclonal antibody (clone EPR3972, ab92377, Abcam, Cambridge, UK), diluted 1:5000 overnight at $4{ }^{\circ} \mathrm{C}$. The membrane was then washed with TBS for $30 \mathrm{~min}$ and incubated with horseradish peroxidase (HRP)-conjugated anti-mouse secondary antibody (Thermoscientific, Rockford, IL, USA), diluted 1:10,000 in $1 \%$ skim milk for $1 \mathrm{~h}$ at room temperature. After washing, the bound antibody was revealed by chemiluminescence using the ECL prime Kit (Bio-Rad, Hercules, CA, USA).

\subsection{Statistical Analysis}

The chi-square test and chi-square test for trend were used to assess the association between TFF1 expression and histological type and the various clinicopathological features of the tumors. The survival time was defined as the interval in days between the date of diagnosis and the date of animal death by natural death and/or euthanasia. Whenever euthanasia was performed during surgery or for reasons related to the deterioration of the animal's health conditions due to the progression of the neoplastic disease, the cause of death was considered to be related to the tumor. Survival time was censored for dogs that were lost to follow up. Kaplan-Meier survival analyses with log-rank test was performed to compare the differences between the median survival time of the two groups preserved and reduced TFF1 immunoexpression. Differences were considered statistically significant at values of $p<0.05$. Analyses were performed using GraphPad Prism 5 (GraphPad Software Inc., La Jolla, CA, USA).

\section{Results}

\subsection{Case Details}

The available epidemiological data (breed, age, sex) and characteristics of the lesions are summarized in Table 1.

The mean age of dogs diagnosed with GPs was 12.1 years \pm 2.6 (range 9-16 years), and the male: female ratio was 5:3. Of the eight GPs, seven were located in the antral region and one at the body region. Five out of eight GPs were classified as hyperplastic polyps and three as inflammatory polyps. All GPs revealed Helicobacter organisms, preferentially located in the hyperplastic foveolae and the lumen of gastric glands.

Gastric carcinomas included in this study were obtained from 19 males $(61.3 \%)$ and 12 females (38.7\%), with a mean age 10.1 years \pm SD 2.6 (range 5-14 years old). There were five crossbreed (16.1\%), four chow-chow (12.9\%), two poodle, two siberian husky, two labrador retriever, two golden retriever, two collie, and twelve dogs of other breeds. Tumors were located in antral region in sixteen cases $(51.6 \%)$, in twelve cases in the gastric body $(38.7 \%)$, in two cases $(6.5 \%)$ the lesion affected both regions, and in the remaining case $(3.2 \%)$ it was not possible to determine the location due to the small size of the biopsy sample. There were six well-differentiated carcinomas (five tubular carcinomas and one papillary carcinoma) and twenty-five poorly/undifferentiated carcinomas (ten signet ring cell carcinomas, eight poorly cohesive carcinomas, five mixed carcinomas, and two mucinous carcinomas). According with Lauren classification, there were six intestinal type, twenty diffuse type, and 5 indeterminate type carcinomas (Figure 1A-E). In two cases, concerning one papillary carcinoma and one signet ring cell carcinoma, there were foci of IM. Regarding to depth of tumor invasion, fifteen carcinomas (48.4\%) invaded the tunica muscularis, twelve $(38.7 \%)$ the serosal layer, three $(9.7 \%)$ were limited to mucosa, and one $(3.2 \%)$ to submucosal layer of the gastric wall. There were $18(58.1 \%)$ cases of GC with neoplastic emboli; however, only 14 neoplastic emboli were available for IHC evaluation. In the remaining four cases, TFF1 analysis in neoplastic emboli was not possible due to tissue exhaustion. Metastatic lesions were diagnosed in nine out of thirty-one cases of GCs. Single and isolated metastases were found in five animals affecting regional lymph nodes $(n=3)$ (Figure $1 F)$, small intestine $(n=1)$, and liver $(n=1)$; another dog presented both lymph node and esophagus involvement $(\mathrm{n}=1)$; in the other cases metastases were 
identified in multiple organs, such as lymph node, pancreas, and intestine $(n=1)$, intestine, peritoneum, and liver $(\mathrm{n}=1)$, and lung, esophagus, liver, and adrenal gland $(\mathrm{n}=1)$. For the immunohistochemical study nine metastatic samples (three intestinal, three regional lymph nodes, one esophagus, one pulmonary, and one adrenal gland metastasis) from eight dogs were also included. Tissue selection criteria were based on the amount of tissue and its conservation conditions.

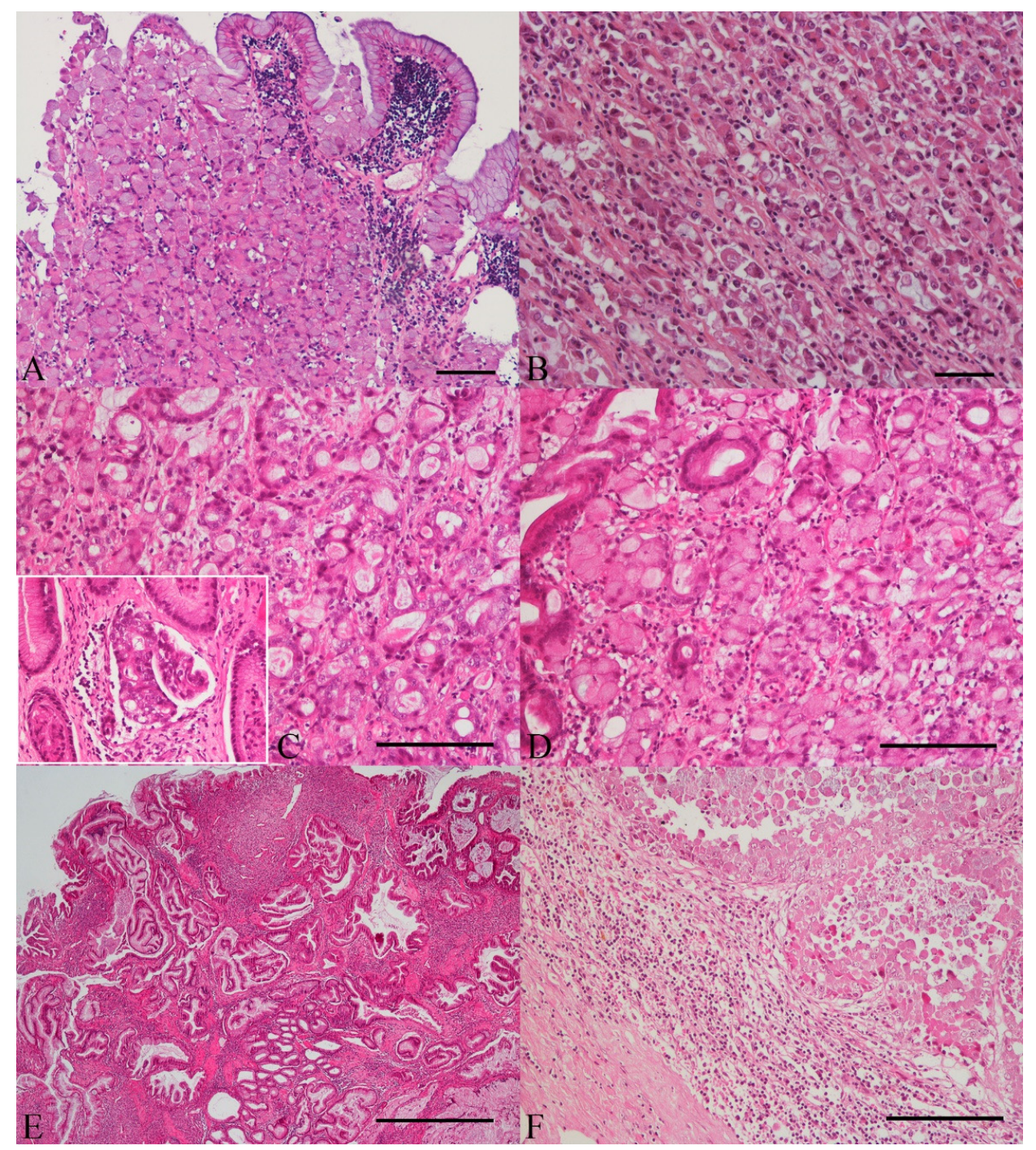

Figure 1. Histopathological features of gastric carcinomas and lymph node metastasis. (A) Signet ring cell carcinoma (WHO) and diffuse type carcinoma (Lauren) constituted by signet ring tumor cells replacing gastric mucosa (bar $=100 \mu \mathrm{m}$ ). (B) Poorly cohesive carcinoma (WHO) and diffuse type carcinoma (Lauren) composed of poorly cohesive tumor cells (bar $=100 \mu \mathrm{m})$. (C,D) Mixed carcinoma (WHO) and indeterminate type carcinoma (Lauren) composed of a mixture of welldifferentiated (tubules of various sizes, C) and signet ring/poorly cohesive histological components (D) $($ bar $=100 \mu \mathrm{m})$. Inset in $\mathbf{C}$ shows neoplastic emboli $(200 \times)$. (E) Tubular carcinoma $(\mathrm{WHO})$ and intestinal type carcinoma (Lauren) characterized by distended, diffuse, or branching tubules of various sizes, sometimes with intraluminal mucus (bar $=500 \mu \mathrm{m})$. (F) Lymph node metastasis of a poorly cohesive carcinoma (WHO) and diffuse type carcinoma (Lauren) with large clusters of neoplastic epithelial cells. Few aggregates of lymphoid cells are still discernible at the periphery (bar $=100 \mu \mathrm{m})$. 
During the study, 21 dogs had died and 10 were lost for follow up after diagnosis. In those whose follow-up data was accomplished, the mean survival time was $31.2 \pm 40.3$ days ( $0-150$ days).

\subsection{Specificity of the Monoclonal Antibody}

The results of Western blot analysis are shown in Figure S1. Anti-estrogen inducible protein pS2 rabbit monoclonal antibody recognized a dominant band near 15 and $20 \mathrm{kDa}$ in the normal canine gastric tissue sample, confirming the specificity of this specific antibody for this species.

\subsection{Immunohistochemistry}

\subsubsection{Normal Gastric Mucosa}

The expression of TFF1 was consistently detected in all normal canine gastric samples $(100 \%)$, covering more than $75 \%$ of the superficial foveolar epithelium and mucopeptic cells of the neck region from both the gastric body (Figure 2A) and antrum (Figure 2B). The predominant staining pattern was diffuse cytoplasmic; a more intense immunostaining was also observed in the apical region of the epithelial cells along the mucosal surface and in the gastric foveolae. Glands of the body region did not show any TFF1 immunoreactivity (Figure 2A). TFF1 immunostaining was also seen in the antral glands, but the intensity of staining was much weaker than the superficial part of the mucosa (Figure 2B).

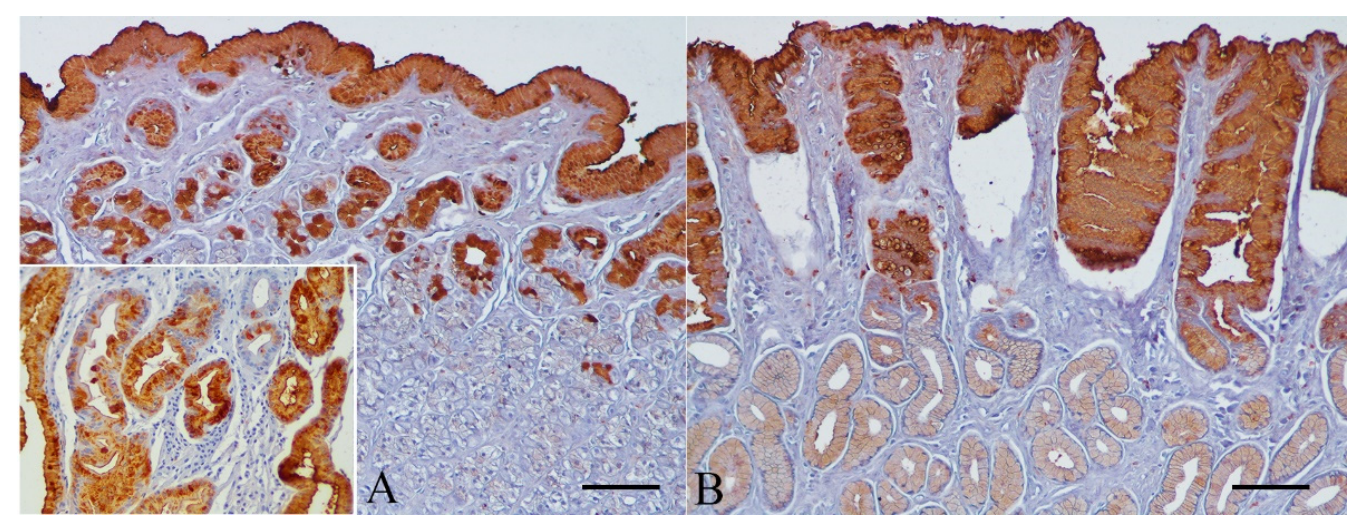

Figure 2. Normal canine gastric mucosa. Immunohistochemistry for TFF1 counterstained with Mayer's hematoxylin. Strong, diffuse, and cytoplasmic TFF1 expression in superficial foveolar epithelium and mucopeptic cells of the neck region from the gastric body (A) and pyloric antrum (B). Note the absence of staining in body glands (A) and the decrease in labeling intensity in the antral glands $(\mathbf{B})(\mathrm{bar}=100 \mu \mathrm{m})$. Inset shows diffuse cytoplasmic TFF1 immunostaining in superficial foveolar epithelium and in the foci of IM of the human gastric mucosa (positive control; $200 \times$ ).

\subsubsection{Gastric Polyps}

All the GPs analyzed presented TFF1 immunoexpression (100\%). In hyperplastic polyps, TFF1 was detected as a diffuse cytoplasm staining in more than $75 \%$ of the cells (Figure 3A). Inflammatory polyps also presented similar subcellular location but affecting more than $75 \%$ of the cells in two cases $(2 / 3,66.7 \%)$ and $25-75 \%$ in $1 / 3(33.3 \%$ ) (Figure 3B). No relevant difference was detected between the scored encountered in these lesions and that found in normal gastric tissue.

\subsubsection{Non-neoplastic Gastric Mucosa Adjacent to Carcinomas}

Non-neoplastic gastric mucosa adjacent to carcinomas was present in 30 out of 31 cases and in all cases, TFF1 immunoexpression was similar to that observed in normal canine gastric mucosa $(100 \%)$. In four of these cases, an intense apical membrane labeling pattern was also detected in the antral glands. 


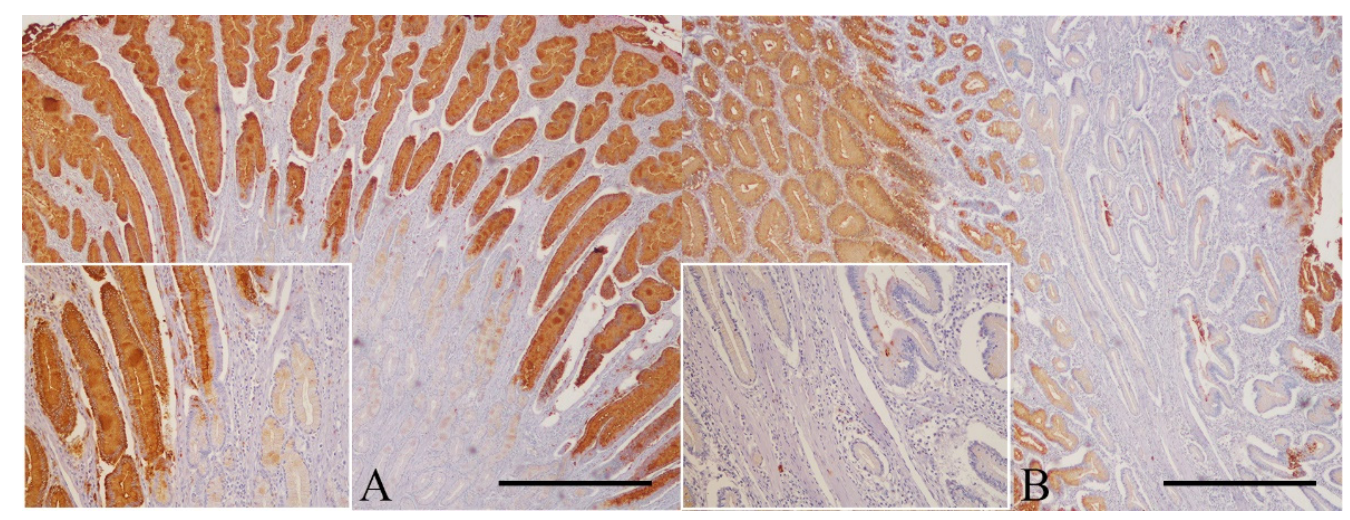

Figure 3. Gastric polyps. Immunohistochemistry for TFF1 counterstained with Mayer's hematoxylin. (A) Hyperplastic polyp: although with different intensity, TFF1 expression is observed in all epithelial components (bar $=500 \mu \mathrm{m})$. Inset shows a higher magnification of TFF1 immunostaining covering superficial epithelium and antral glands $(200 \times)$. (B) Inflammatory polyp: some glands do not display TFF1 expression, in contrast with the strong immunolabeling of superficial gastric mucosa (bar $=500 \mu \mathrm{m})$. Inset high shows the reduced expression of TFF1 in the antral glands $(200 \times)$.

\subsubsection{Gastric Carcinomas}

Twenty-three out of the 31 malignant lesions (74.2\%) showed reduced TFF1 expression, characterized by absence of staining in five cases (all diffuse type carcinomas) (Figure 4A) and decreased expression in eighteen cases (eleven diffuse type, four indeterminate type, and three intestinal type carcinomas) (Figure 4B-E), compared with that observed in normal gastric mucosa. In the remaining eight cases, TFF1 expression was preserved (four diffuse type, three intestinal type, and one indeterminate type carcinomas) (Figure 4F). At the subcellular level, the pattern of TFF1 was mainly diffuse cytoplasmic, but occasionally immunostaining was also seen in apical membrane and luminal secretions of the intestinal (tubular) component. The expression of TFF1 was observed to gradually decrease from mucosa to deeper layers of the gastric wall. In the foci of IM, no TFF1 immunoexpression was recorded in one case (Figure 4E). In the other case, it was not possible to evaluate TFF1 expression in IM due to tissue exhaustion.

The level of TFF1 expression showed a decreased tendency from normal gastric mucosa $(100 \%)$ to GPs $(87.5 \%)$ and to GCs $(25.8 \%)$ and this reduction in protein expression was statistically significant ( $p=0.0003$; Figure 5).

Table 2 summarizes the results of association analysis between clinicopathological features of the tumors and TFF1 immunoexpression. Reduced expression of TFF1 was more frequent, though not significantly, in poorly/undifferentiated carcinomas (80\%) and, in indeterminate and diffuse type carcinomas ( $80 \%$ and $80 \%$, respectively) than in well-differentiated or intestinal type carcinomas $(50 \%, p=0.132$ and $p=0.229)$.

Fifteen out of the $23(65.2 \%)$ carcinomas with reduced expression of TFF1 presented neoplastic emboli, but it was not statistically significant $(p=0.171)$. Although not statistically significant, most GCs cases with the presence of metastatic disease $(88.9 \%)$ displayed a reduced expression of TFF1 $(p=0.186)$. The labeling pattern of TFF1 in neoplastic emboli and metastases was further compared with that found on the primary lesion. Nine out of fourteen neoplastic emboli showed higher expression, two had similar expression, and in three cases the expression was lower than in the primary tumors. Compared to primary neoplasms, four metastatic lesions exhibited similar expression, three had lower expression and two showed higher expression.

When comparing survival times between the two groups (preserved and reduced TFF1 immunoexpression), the median survival times of animals with preserved TFF1 immunoexpression was 30 days and the median survival times of animals with reduced TFF1 immunoexpression was 12.0 days. Kaplan-Meier survival analysis revealed no significant survival differences between the two cohorts (log-rank test, $p=0.5976$ ). 


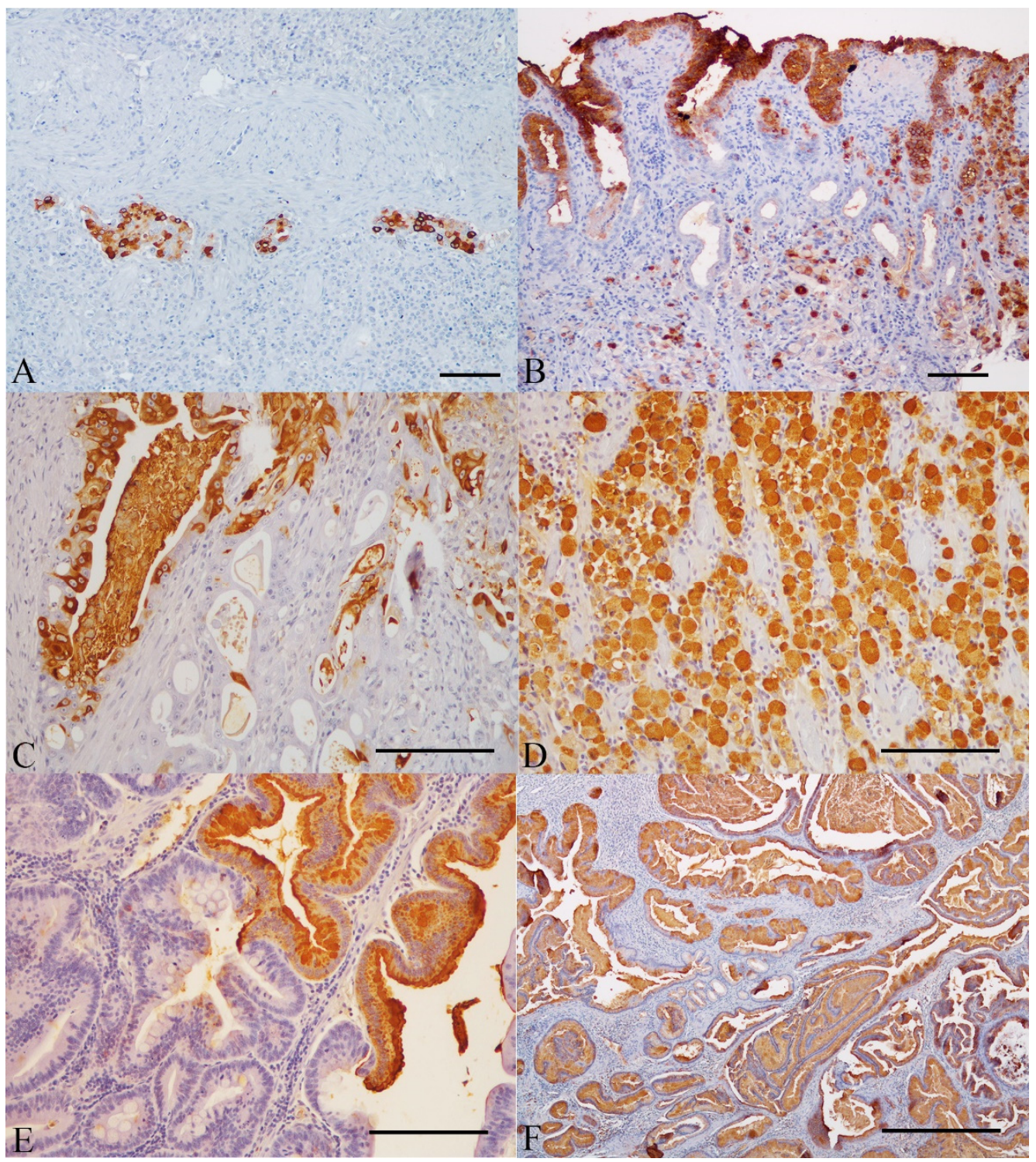

Figure 4. Gastric carcinomas. Immunohistochemistry for TFF1 counterstained with Mayer's hematoxylin. (A) Absence of TFF1 expression ( $<5 \%$ of immunoreactive cells) in a poorly cohesive carcinoma (WHO) and diffuse type carcinoma (Lauren) and increased expression of TFF1 in neoplastic emboli (bar $=100 \mu \mathrm{m})$. (B) Reduced expression of TFF1 (25-75\% of immunoreactive cells) in a signet ring cell carcinoma (WHO) and diffuse type carcinoma (Lauren) (bar $=100 \mu \mathrm{m})$. Note the intense TFF1 expression in adjacent superficial gastric mucosa. (C,D) Reduced expression of TFF1 (25-75\% of immunoreactive cells) in a mixed carcinoma (WHO) and indeterminate type carcinoma (Lauren). Note reduced expression of TFF1 (25-75\% of immunoreactive cells) in the intestinal (tubular) component while in diffuse component the expression was preserved ( $>75 \%$ of immunoreactive cells) $($ bar $=100 \mu \mathrm{m})$. (E) No TFF1 expression was observed in the foci of IM in a papillary carcinoma $(\mathrm{WHO})$ and intestinal type carcinoma (Lauren) $(\mathrm{bar}=100 \mu \mathrm{m})$. (F) Preserved expression of TFF1 ( $>75 \%$ of immunoreactive cells) in a tubular carcinoma (WHO) and intestinal type carcinoma (Lauren) (bar $=500 \mu \mathrm{m})$. 


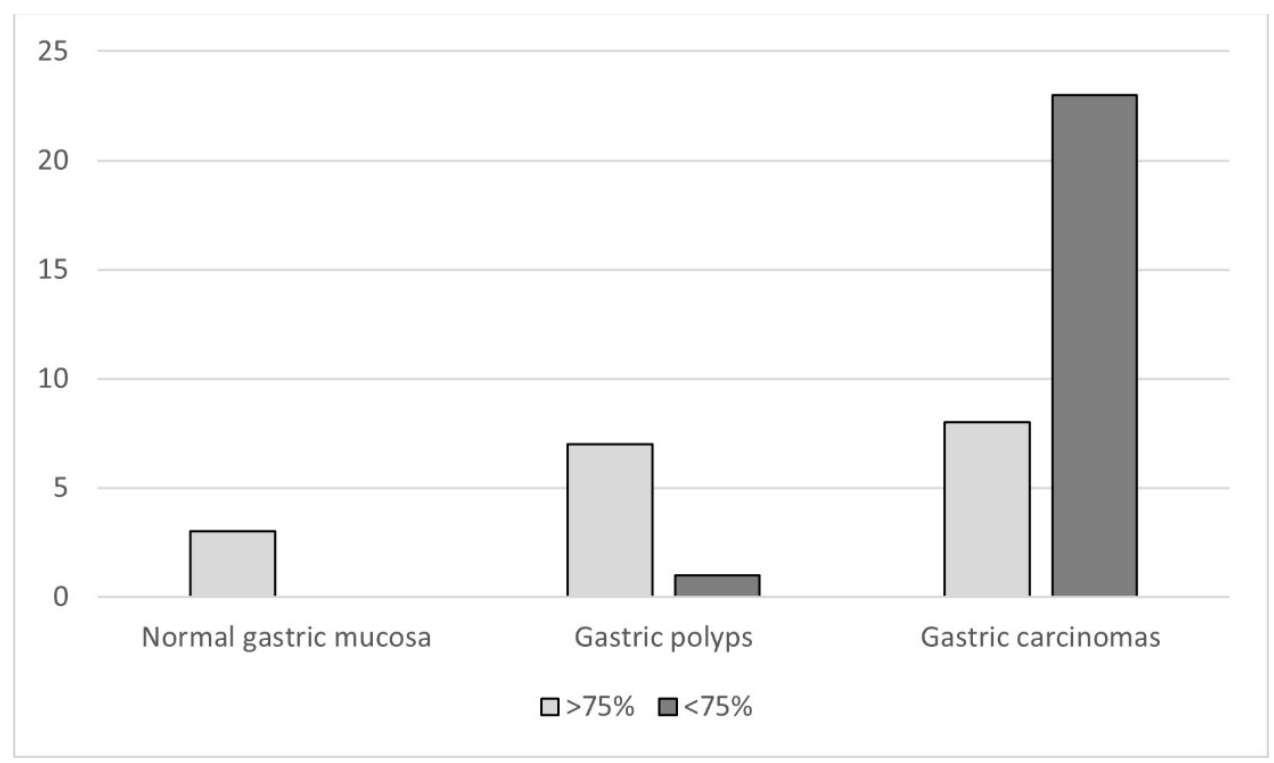

Figure 5. Expression of TFF1 by histological type $(p=0.0003)$.

Table 2. Association between TFF1 expression and clinicopathological features in 31 canine gastric carcinomas.

\begin{tabular}{|c|c|c|c|c|}
\hline \multirow[b]{2}{*}{ Parameter } & \multirow[b]{2}{*}{ No. of Cases } & \multicolumn{3}{|c|}{ TFF1 Immunoreactivity } \\
\hline & & $\begin{array}{c}\text { Preserved } \\
\mathrm{N}=8(25.8 \%)\end{array}$ & $\begin{array}{c}\text { Reduced } \\
\mathrm{N}=23(74.2 \%)\end{array}$ & $p$-Value \\
\hline \multicolumn{5}{|l|}{ Sex } \\
\hline Male & 19 & $4(21.1)$ & $15(78.9)$ & \multirow{2}{*}{0.447} \\
\hline Female & 12 & $4(33.3)$ & $8(66.7)$ & \\
\hline \multicolumn{5}{|l|}{ Age, years } \\
\hline$<10$ & 12 & $2(16.7)$ & $10(83.3)$ & \multirow{2}{*}{0.355} \\
\hline$\geq 10$ & 19 & $6(31.6)$ & $13(68.4)$ & \\
\hline \multicolumn{5}{|l|}{ Tumor location ${ }^{1}$} \\
\hline Antrum & 16 & $6(37.5)$ & $10(62.5)$ & \multirow{3}{*}{0.317} \\
\hline Body & 12 & $2(16.7)$ & $10(83.3)$ & \\
\hline Body + antrum & 2 & $0(0)$ & $2(100)$ & \\
\hline \multicolumn{5}{|l|}{ Histological diagnosis } \\
\hline WHO classification [31] & & & & \multirow{3}{*}{0.132} \\
\hline Well-differentiated & 6 & $3(50)$ & $3(50)$ & \\
\hline Poorly/undifferentiated & 25 & $5(20)$ & $20(80)$ & \\
\hline \multicolumn{5}{|l|}{ Lauren [32] } \\
\hline Intestinal & 6 & $3(50)$ & $3(50)$ & \multirow{3}{*}{0.229} \\
\hline Diffuse & 20 & $4(20)$ & $16(80)$ & \\
\hline Indeterminate & 5 & $1(20)$ & $4(80)$ & \\
\hline \multicolumn{5}{|l|}{ Depth of tumor invasion 2} \\
\hline Muscular & 10 & $3(30)$ & $7(70)$ & \multirow[t]{2}{*}{0.457} \\
\hline Serosa & 12 & $2(16.7)$ & $10(83.3)$ & \\
\hline \multicolumn{5}{|l|}{ Neoplastic emboli } \\
\hline Present & 18 & $3(16.7)$ & $15(83.3)$ & \multirow[t]{2}{*}{0.171} \\
\hline Absent & 13 & $5(38.5)$ & $8(61.5)$ & \\
\hline \multicolumn{5}{|l|}{ Metastatic lesions ${ }^{3}$} \\
\hline Present & 9 & $1(11.1)$ & $8(88.9)$ & \multirow[t]{2}{*}{0.186} \\
\hline Absent & 17 & $6(35.3)$ & $11(64.7)$ & \\
\hline
\end{tabular}




\section{Discussion}

The role of TFF1 or pS2 in gastric carcinogenesis has been investigated in several human and mouse models, and it has been proposed that it might act as a tumor suppressor factor [24,28]. Previously, Campbell and Jabbes [29] have sequenced canine and feline TFFs cDNAs derived from gastric (TFF1, TFF2) and colonic (TFF3) mucosa RNA and showed that the majority of the deduced amino acid sequences of canine and feline TFFs obtained were in agreement with those of other mammalian species (e.g., human, rat, mouse, cow, pig, sheep), supporting the theory that the dog and cat may prove to be useful models for the study of trefoil peptides in various pathologies, such as IBD and gastrointestinal carcinomas. The present study was carried out to investigate whether there is a relationship between TFF1 immunoreactivity and canine gastric carcinogenesis.

Our study was conducted on eight GPs and thirty-one GCs. Reinforcing previous data, herein the dogs affected with GPs were males [1]. The most common was the hyperplastic type, and the lesions were preferentially located in the gastric antrum. Concerning GCs, the male predilection and mean age recorded in this series agree with those of others [1,35]. In literature, a breed predisposition has been reported in belgian shepherd dogs, rough collies, staffordshire terriers, chow-chows, and standard poodles [1]. In the present study, crossbreed dogs predominate (five dogs or 16.1\%) followed by chow-chow (four dogs or $12.9 \%)$. In this series, there was a predominance of signet ring cell $(10 / 31)$ and diffuse type (20/31) carcinomas, according with the human WHO and Lauren classifications, respectively. Our findings are keeping with previous studies in dogs $[8,35,36]$. Furthermore, our data support the preferential location of GCs in the antral region [8,35]. Additionally, the mean survival time for dogs with GCs was 31.2 days, which goes towards the reported 35 days proposed by Swann and Holt [37].

Our findings in normal canine gastric mucosa are in accordance with those previously reported regarding normal human [12,25,34] and mouse gastric tissues [38]. TFF1 was ubiquitously expressed in the superficial foveolar epithelium of the oxyntic and antral mucosa of the dogs. In addition, the predominantly cytoplasm subcellular location, with a more intense immunostaining in the apical region, supports the notion that TFF1 gene encodes a secretory protein. Similarly, to human studies $[12,25,26,34]$, we also observed weak immunostaining for TFF1 in antral glands. Previously, Ren et al. [39] evaluated the molecular forms of TFF1 in human normal gastric mucosa and found three patterns of TFF1: monomer (6.5 kDa), dimmer (13 kDa), and TFF1 compound (about $21 \mathrm{kDa})$, suggesting that the biological activity of TFF1 may be related to formation of homologous dimmer or other oligomers composed of heterogenous proteins. In the present study, a Western blot analysis using an anti-estrogen inducible protein pS2 rabbit monoclonal antibody (clone EPR3972) demonstrated that in normal canine gastric mucosa, TFF1 has a molecular weight near 15 and $20 \mathrm{kDa}$. Collectively, our observations validate the specificity and cross-reactivity of this specific antibody with canine tissues. We speculate that TFF1 found in normal gastric mucosa is composed of TFF1 and its receptor, transport protein, or some glycoprotein. Further studies are needed to explore the molecular forms of TFF1 in normal canine gastric mucosa and abnormal gastric tissues.

Machado et al. [12] and Nogueira et al. [34] evaluated the expression of TFF1 in human GPs and found a consistent expression of TFF1 in all the hyperplastic polyps analyzed $(n=10)$. In the present study, the expression of TFF1 in GPs was also consistently observed in all cases, displaying an immunopattern analogous to that of normal canine gastric mucosa. Our findings are in accordance with human studies and reinforce our previous investigations $[10,16]$ in which canine GPs are considered merely proliferative lesions, at least phenotypically very similar to normal canine gastric epithelium.

In the present study, we found two GCs with foci of IM and the one only available for TFF1 testing did not reveal any immunoexpression in the metaplastic cells. The expression of TFF1 in normal gastric mucosa together with the absence of immunoreactivity in IM fit the hypothesis that TFF1 can be used as a marker of gastric differentiation, as observed 
in human studies $[25,26]$. However, further studies are needed to prove the usefulness of TFF1 protein as a marker of gastric differentiation in dogs.

In GCs, TFF1 expression was found reduced in $74.2 \%$ of the cases, a frequency that is close to that reported by Moss et al. [40] ( $>70 \%)$ but above that reported by Wu et a., [41], Im et al. [42], and Muller and Borchard [26] (58.3\%, 53.8\%, and 48\%, respectively) in human GCs series. The difference in the percentage obtained in this study and those from human GCs series may be related to the species in question (human vs. dog), to the antibodies against TFF1 used, and to the scoring system adopted for the immunoreactivity evaluation.

Tanaka and colleagues [43] found, in a series of 182 human GCs, that low expression of TFF1 was significantly correlated with deeper invasion of the tumor. They also found in the in vitro analysis that the invasive activity of gastric cancer cells increased significantly in TFF1-deficient cells compared with the control cells [43]. In the present study, the expression of TFF1 was observed to gradually decreased from mucosa to deeper layers, suggesting that the loss or reduction of this protein may confer an invasive phenotype to canine gastric neoplastic cells and thus promote cancer progression. Similar findings were discussed by Sunagawa et al. [44] who reported lost or decreased expression of TFF1 in the tumor invasion front of human pancreatic ductal adenocarcinomas (PDAC). Based on these findings, they speculated that the loss of TFF1 resulted in the epithelial-mesenchymal transition (EMT) of tumor cells and, therefore, upregulation of TFF1 might inhibit the EMT in cancer cells. During EMT, epithelial cells change their phenotype, exhibiting a reduction in cell-cell contacts, loss of polarity, increased cell motility and invasiveness, repression of epithelial cell markers (e.g., epithelial cells adhesion molecule (EpCAM), cytokeratin (CK), or E-cadherin), and aberrant upregulation of certain mesenchymal markers (e.g., vimentin and N-cadherin) [45]. Indeed, a recent study demonstrated that the overexpression of TFF1 inhibits EMT through regulation of TGF- $\beta$ in gastric cancer cells. The authors found that elevated TFF1 levels induced the expression of E-cadherin, and reduced the expression of vimentin, $\mathrm{N}$-cadherin, and others well-known repressors of E-cadherin expression.

We observed a significant decrease in the TFF1 expression level from normal gastric mucosa to GPs and to GCs. These findings suggest that TFF1 may have a role in maintenance of normal canine gastric mucosal integrity, and that the loss of TFF1 may be associated with the malignant transformation of gastric mucosa. Hence, we speculated that TFF1 may act as a tumor suppressor during canine gastric carcinogenesis, as previously mentioned for human and mouse species [24]. In human gastric cancer, there are two probable causes for the low expression or absence of TFF1: 1) potential genetic alterations, including gene mutation, loss of heterozygosity $(\mathrm{LOH})$, and DNA methylation; 2 ) poorly differentiated cells and glands, which are extremely altered to secrete TFF1 $[39,43,46]$. Future studies are needed in order to elucidate the precise mechanism behind reduced TFF1 expression and its involvement in canine gastric carcinogenesis.

Controversial data have been found regarding the expression of TFF1 in human GCs based on histological subtype. Im and coworkers [42] reported a much higher frequency of TFF1 expression in undifferentiated and diffuse type carcinomas compared with differentiated and intestinal type carcinomas. In contrast, Shi et al. [47] found that the expression level of TFF1 was lower in poorly differentiated carcinomas than in well-differentiated carcinomas. In the present study, the frequency of carcinomas displaying a reduced expression of TFF1 was higher in poorly/undifferentiated carcinomas (80\%) and, in indeterminate and diffuse type (80\% and $80 \%$, respectively) carcinomas than in well-differentiated and intestinal type carcinomas (50\%), respectively. However, this difference was not statistically significant.

We found no significant difference between TFF1 expression and the presence of neoplastic emboli and metastatic disease. These findings concur with previous reports $[42,48]$ in human GCs but contrast with those of Machado et al. [25] who found a significant association between TFF1 expression and lymph node metastases. However, we observed that the expression of TFF1 in neoplastic emboli was generally higher than that of the corresponding primary lesion. Given the higher expression of TFF1 in circulating neoplastic cells, we 
speculate that TFF1 can be detected in the serum, and, therefore, might be applicable in clinical practice as a non-invasive biomarker for the screening of gastric cancer progression. We also found that TFF1 expression in metastases was equal to or greater than that of the primary tumor. The expression of TFF1 in metastatic lesions suggests that neoplastic cells that have traveled to other tissues try, as soon as they arrive, to maintain or re-establish at least some of their original biological properties, namely by restoring common TFF1 expression of normal gastric epithelial cells. In the future, it would be interesting to explore this theory, analyzing a greater number of cases of patients with metastases.

In domestic animals, although some potential prognostic markers have been investigated in canine GC (such as HER-3, HER-2, EGFR, and KRAS), its value as prognostic indicators were not demonstrated [35,49] probably due to small numbers of reported neoplasms and also the lack of a complete clinical history and follow-up. In the present study we investigate whether the immunohistochemical evaluation of TFF1 carries any meaningful prognostic information for canine GCs. A small difference that did not reach statistical significance between the median survival times of dogs with preserved TFF1 (30 days) and reduced TFF1 tumors (12days) was found. The lack of correlation between TFF1 expression and survival of human gastric cancer patients was reported by several authors $[25,26,41]$; however, Suarez et al. [48] reported that high intratumoral TFF1 levels were significantly associated with an unfavorable outcome.

Some limitations of this study are the reduced number of cases, subjected to different sampling methods (partial vs. full-thickness biopsies), and submitted to different and not standardize clinical approaches. Additionally, the survival time may not be exact since the cases submitted to euthanasia were based on clinical decisions and may cover different stages of the oncological disease. Notwithstanding, this investigation represents an important contribution for the study of canine gastric carcinogenesis, as it gathers epidemiological and histopathological information from a group of dogs whose gastric lesions were the target of a pioneer study using an important antibody considered a tumor suppressor in cases of human gastric cancer.

\section{Conclusions}

In conclusion, the present study revealed a significant reduction in the expression of TFF1 in GCs when compared with GPs and normal gastric mucosa, which suggests that TFF1 may act as a tumor suppressor during canine gastric carcinogenesis. Additionally, there was a gradual decrease in TFF1 expression from mucosa to deeper layers, suggesting that the loss or reduction of this protein may confer an invasive phenotype on canine gastric neoplastic cells and thus promote cancer progression. Further studies on a larger number of cases and clinical follow-ups are necessary to define, with greater scientific accuracy, the clinical significance of TFF1 and its usefulness as a prognostic indicator.

The pathological and behavioral similarities between spontaneous canine and humans' carcinomas make it logical to assume that dogs may be a useful model for human gastric cancer.

Supplementary Materials: The following are available online at https:/ / www.mdpi.com/article/10 .3390 /ani11102855/s1, Figure S1: Western blot analysis of anti-estrogen inducible protein pS2 rabbit monoclonal antibody in normal canine gastric mucosa. (1) Normal canine gastric mucosa protein extract. Presence of a dominant band near 15 and $20 \mathrm{kDa}$.

Author Contributions: Conceptualization, A.R.F. and I.A.; methodology, A.R.F., M.C., A.R., and J.R.M.; validation, M.T., F.S., and I.A.; formal analysis, A.R.F., F.S., and I.A.; investigation, A.R.F., F.S., and I.A.; data curation, A.R.F., M.T., and I.A.; writing—original draft preparation, A.R.F.; writingreview and editing, all authors; supervision, F.G., F.S., and I.A. All authors have read and agreed to the published version of the manuscript.

Funding: IPATIMUP integrates the i3S Research Unit, which is partially supported by FEDER through the Operational Programme for Competitiveness Factors-COMPETE and National Funds 
through the Portuguese Foundation for Science and Technology (FCT), under the project number PEst-C/SAU/LA0003/2013.

Institutional Review Board Statement: Ethical review and approval were waived for this study, due to the fact that the samples were submitted for diagnostic purpose as part of clinical case workup.

Data Availability Statement: The data presented in this study is contained within the manuscript.

Acknowledgments: A.R. Flores (SFRH/BD/116373/2016) acknowledges FCT, the Portuguese Foundation for Science and Technology, for financial support. The authors of the research unit CECAV also received funding from the project UIDB/CVT/0772/2020.

Conflicts of Interest: The authors declare no conflict of interest.

\section{References}

1. Amorim, I.; Taulescu, M.A.; Day, M.J.; Catoi, C.; Reis, C.A.; Carneiro, F.; Gärtner, F. Canine Gastric Pathology: A Review. J. Comp. Pathol. 2016, 154, 9-37. [CrossRef]

2. Gualtieri, M.; Costa Devoit, C.; Riccardi, E.; Olivero, D. Intestinal Metaplasia and Over-Expression of c-erb2 and p53 in Tissue Adjacent to Dog Gastric Carcinoma. Pak. Vet. J. 2017, 37, 269-274.

3. Abrams, B.; Wavreille, V.A.; Husbands, B.D.; Matz, B.M.; Massari, F.; Liptak, J.M.; Cray, M.T.; de Mello Souza, C.H.; WustefeldJanssens, B.G.; Oblak, M.L.; et al. Perioperative complications and outcome after surgery for treatment of gastric carcinoma in dogs: A Veterinary Society of Surgical Oncology retrospective study of 40 cases (2004-2018). Vet. Surg. 2019, 48, 923-932. [CrossRef] [PubMed]

4. Head, K.W.; Cullen, J.M.; Dubielzig, R.R.; Else, R.W.; Misdorp, W.; Patnaik, A.K.; Tateyama, S.; van der Gaag, I. Histological Classification of Tumors of the Alimentary System of Domestic Animals; Armed Forces Institute of Pathology: Washington, DC, USA, 2003; Volume 10, pp. 73-110.

5. Koterbay, A.M.; Muthupalani, S.; Fox, J.G.; McNiel, E.A. Risk and characteristics of gastric carcinoma in the chow chow dog. Can. Vet. J. 2020, 61, 396-400. [PubMed]

6. Watanabe, H.; Jass, J.; Sobin, L.; Ota, K.; Jass, J. Histological typing of oesophageal and gastric tumours. In WHO International Histological Classification of Tumours, 2nd ed.; Springer: Berlin, Germany, 1990; pp. 5-9. [CrossRef]

7. Patnaik, A.K.; Hurvitz, A.I.; Johnson, G.F. Canine gastric adenocarcinoma. Vet. Pathol. 1978, 15, 600-607. [CrossRef] [PubMed]

8. Fonda, D.; Gualtieri, M.; Scanziani, E. Gastric carcinoma in the dog: A clinicopathological study of 11 cases. J. Small Anim. Pract. 1989, 30, 353-360. [CrossRef]

9. Janke, L.; Carlson, C.S.; St Hill, C.A. The novel carbohydrate tumor antigen C2-O-sLe x is upregulated in canine gastric carcinomas. Vet. Pathol. 2010, 47, 455-461. [CrossRef] [PubMed]

10. Flores, A.R.; Lemos, I.; Rema, A.; Taulescu, M.; Seixas, F.; Reis, C.A.; Gärtner, F.; Amorim, I. Tn and Sialyl-Tn antigens in canine gastric tissues. Veter-Comp. Oncol. 2020, 18, 615-625. [CrossRef]

11. Carneiro, F.; David, L.; Seruca, R.; Castedo, S.; Nesland, J.M.; Sobrinho-Simões, M. Hyperplastic polyposis and diffuse carcinoma of the stomach. A study of a family. Cancer 1993, 72, 323-329. [CrossRef]

12. Machado, J.C.; Carneiro, F.; Blin, N.; Sobrinho-Simões, M. Pattern of pS2 protein expression in premalignant and malignant lesions of gastric mucosa. Eur. J. Cancer Prev. 1996, 5, 169-179. [CrossRef]

13. Lecoindre, P.; Bystricka, M.; Chevallier, M.; Peyron, C. Gastric carcinoma associated with Menetrier's-like disease in a West Highland white terrier. J. Small Anim. Pract. 2012, 53, 714-718. [CrossRef]

14. Qvigstad, G.; Kolbjørnsen, Ø.; Skancke, E.; Waldum, H.L. Gastric neuroendocrine carcinoma associated with atrophic gastritis in the norwegian lundehund. J. Comp. Pathol. 2008, 139, 194-201. [CrossRef]

15. Munday, J.S.; Aberdein, D.; Cullen, G.D.; French, A.F. Ménétrier disease and gastric adenocarcinoma in 3 Cairn terrier littermates. Vet. Pathol. 2012, 49, 1028-1031. [CrossRef] [PubMed]

16. Amorim, I.; Taulescu, M.A.; Ferreira, A.; Rêma, A.; Reis, C.A.; Faustino, A.M.; Cătoi, C.; Gärtner, F. An immunohistochemical study of canine spontaneous gastric polyps. Diagn. Pathol. 2014, 9, 166. [CrossRef] [PubMed]

17. Aihara, E.; Engevik, K.A.; Montrose, M.H. Trefoil Factor Peptides and Gastrointestinal Function. Annu. Rev. Physiol. 2017, 79, 357-380. [CrossRef] [PubMed]

18. Busch, M.; Dünker, N. Trefoil factor family peptides-Friends or foes? Biomol. Concepts 2015, 6, 343-359. [CrossRef] [PubMed]

19. Masiakowski, P.; Breathnach, R.; Bloch, J.; Gannon, F.; Krust, A.; Chambon, P. Cloning of cDNA sequences of hormone-regulated genes from the MCF-7 human breast cancer cell line. Nucleic Acids Res. 1982, 10, 7895-7903. [CrossRef]

20. Thim, L. Trefoil peptides: From structure to function. Cell. Mol. Life Sci. CMLS 1997, 53, 888-903. [CrossRef]

21. Rio, M.C.; Bellocq, J.P.; Daniel, J.Y.; Tomasetto, C.; Lathe, R.; Chenard, M.P.; Batzenschlager, A.; Chambon, P. Breast cancerassociated pS2 protein: Synthesis and secretion by normal stomach mucosa. Science 1988, 241, 705-708. [CrossRef] [PubMed]

22. Lefebvre, O.; Wolf, C.; Kédinger, M.; Chenard, M.P.; Tomasetto, C.; Chambon, P.; Rio, M.C. The mouse one P-domain (pS2) and two P-domain (mSP) genes exhibit distinct patterns of expression. J. Cell Biol. 1993, 122, 191-198. [CrossRef] [PubMed]

23. May, F.E.; Westley, B.R. Trefoil proteins: Their role in normal and malignant cells. J. Pathol. 1997, 183, 4-7. [CrossRef] 
24. Lefebvre, O.; Chenard, M.P.; Masson, R.; Linares, J.; Dierich, A.; LeMeur, M.; Wendling, C.; Tomasetto, C.; Chambon, P.; Rio, M.C. Gastric mucosa abnormalities and tumorigenesis in mice lacking the pS2 trefoil protein. Science 1996, 274, 259-262. [CrossRef] [PubMed]

25. Machado, J.C.; Carneiro, F.; Ribeiro, P.; Blin, N.; Sobrinho-Simões, M. pS2 protein expression in gastric carcinoma. An immunohistochemical and immunoradiometric study. Eur. J. Cancer 1996, 32, 1585-1590. [CrossRef]

26. Müller, W.; Borchard, F. pS2 protein in gastric carcinoma and normal gastric mucosa: Association with clincopathological parameters and patient survival. J. Pathol. 1993, 171, 263-269. [CrossRef]

27. Luqmani, Y.; Bennett, C.; Paterson, I.; Corbishley, C.M.; Rio, M.C.; Chambon, P.; Ryall, G. Expression of the pS2 gene in normal, benign and neoplastic human stomach. Int. J. Cancer 1989, 44, 806-812. [CrossRef]

28. Mao, W.; Chen, J.; Peng, T.-L.; Yin, X.-F.; Chen, L.-Z.; Chen, M.-H. Role of trefoil factor 1 in gastric cancer and relationship between trefoil factor 1 and gastrokine 1. Oncol. Rep. 2012, 28, 1257-1262. [CrossRef]

29. Campbell, B.G.; Jabbes, M. Canine and feline trefoil factor family peptides: Highly conserved molecules with some unique characteristics. Res. Vet. Sci. 2008, 85, 68-73. [CrossRef]

30. Schmitz, S.; Hill, S.; Werling, D.; Allenspach, K. Expression of trefoil factor genes in the duodenum and colon of dogs with inflammatory bowel disease and healthy dogs. Veter-Immunol. Immunopathol. 2013, 151, 168-172. [CrossRef]

31. Bosman, F.T.; Carneiro, F.; Hruban, R.H.; Theise, N.D. WHO Classification of Tumors of the Digestive System; IARC Press: Lyon, France, 2010; Volume 3.

32. Lauren, P. The Two Histological Main Types of Gastric Carcinom: Diffuse and So-Called Intestinal-Type Carcinoma. An Attempt at a Histo-Clinical Classification. Acta Pathol. Microbiol. Scand. 1965, 64, 31-49. [CrossRef]

33. Prachasilpchai, W.; Nuanualsuwan, S.; Chatsuwan, T.; Techangamsuwan, S.; Wangnaitham, S.; Sailasuta, A. Diagnosis of Helicobacter spp. infection in canine stomach. J. Veter-Sci. 2007, 8, 139-145. [CrossRef] [PubMed]

34. Nogueira, A.M.; Machado, J.C.; Carneiro, F.; Reis, C.A.; Gött, P.; Sobrinho-Simões, M. Patterns of expression of trefoil peptides and mucins in gastric polyps with and without malignant transformation. J. Pathol. 1999, 187, 541-548. [CrossRef]

35. Terragni, R.; Casadei Gardini, A.; Sabattini, S.; Bettini, G.; Amadori, D.; Talamonti, C.; Vignoli, M.; Capelli, L.; Saunders, J.H.; Ricci, M.; et al. EGFR, HER-2 and KRAS in canine gastric epithelial tumors: A potential human model? PLoS ONE 2014, 9, e85388. [CrossRef] [PubMed]

36. Carrasco, V.; Canfrán, S.; Rodríguez-Franco, F.; Benito, A.; Sáinz, A.; Rodríguez-Bertos, A. Canine gastric carcinoma: Immunohistochemical expression of cell cycle proteins (p53, p21, and p16) and heat shock proteins (Hsp27 and Hsp70). Vet. Pathol. 2011, 48, 322-329. [CrossRef] [PubMed]

37. Swann, H.M.; Holt, D.E. Canine gastric adenocarcinoma and leiomyosarcoma: A retrospective study of 21 cases (1986-1999) and literature review. J. Am. Anim. Hosp. Assoc. 2002, 38, 157-164. [CrossRef]

38. Karam, S.M.; Tomasetto, C.; Rio, M.C. Trefoil factor 1 is required for the commitment programme of mouse oxyntic epithelial progenitors. Gut 2004, 53, 1408-1415. [CrossRef] [PubMed]

39. Ren, J.L.; Luo, J.Y.; Lu, Y.P.; Wang, L.; Shi, H.X. Molecular forms of trefoil factor 1 in normal gastric mucosa and its expression in normal and abnormal gastric tissues. World J. Gastroenterol. 2006, 12, 7361-7364. [CrossRef]

40. Moss, S.F.; Lee, J.W.; Sabo, E.; Rubin, A.K.; Rommel, J.; Westley, B.R.; May, F.E.; Gao, J.; Meitner, P.A.; Tavares, R.; et al. Decreased expression of gastrokine 1 and the trefoil factor interacting protein TFIZ1/GKN2 in gastric cancer: Influence of tumor histology and relationship to prognosis. Clin. Cancer Res. Off. J. Am. Assoc. Cancer Res. 2008, 14, 4161-4167. [CrossRef]

41. Wu, M.S.; Shun, C.T.; Wang, H.P.; Lee, W.J.; Wang, T.H.; Lin, J.T. Loss of pS2 protein expression is an early event of intestinal-type gastric cancer. Jpn. J. Cancer Res. 1998, 89, 278-282. [CrossRef]

42. Im, S.; Yoo, C.; Jung, J.H.; Choi, H.J.; Yoo, J.; Kang, C.S. Reduced expression of TFF1 and increased expression of TFF3 in gastric cancer: Correlation with clinicopathological parameters and prognosis. Int. J. Med. Sci. 2013, 10, 133-140. [CrossRef]

43. Tanaka, T.; Nakamura, J.; Kitajima, Y.; Kai, K.; Miyake, S.; Hiraki, M.; Ide, T.; Koga, Y.; Noshiro, H. Loss of trefoil factor 1 is regulated by DNA methylation and is an independent predictive factor for poor survival in advanced gastric cancer. Int. J. Oncol. 2013, 42, 894-902. [CrossRef] [PubMed]

44. Sunagawa, M.; Yamaguchi, J.; Kokuryo, T.; Ebata, T.; Yokoyama, Y.; Sugawara, G.; Nagino, M. Trefoil factor family 1 expression in the invasion front is a poor prognostic factor associated with lymph node metastasis in pancreatic cancer. Pancreatology 2017, 17, 782-787. [CrossRef] [PubMed]

45. Nakamura, K.; Iwatsuki, M.; Kurashige, J.; Ishimoto, T.; Baba, Y.; Miyamoto, Y.; Yoshida, N.; Watanabe, M.; Baba, H. Circulating tumor cells in gastric cancer. J. Cancer Metastasis Treat. 2018, 4, 32. [CrossRef]

46. Feng, G.; Zhang, Y.; Yuan, H.; Bai, R.; Zheng, J.; Zhang, J.; Song, M. DNA methylation of trefoil factor 1 (TFF1) is associated with the tumorigenesis of gastric carcinoma. Mol. Med. Rep. 2014, 9, 109-117. [CrossRef]

47. Shi, S.Q.; Cai, J.T.; Yang, J.M. Expression of trefoil factors 1 and 2 in precancerous condition and gastric cancer. World J. Gastroenterol. 2006, 12, 3119-3122. [CrossRef]

48. Suárez, C.; Vizoso, F.; Rodríguez, J.C.; García, I.; Raigoso, P.; Allende, M.T.; García-Muñíz, J.L.; García-Morán, M. Prognostic significance of cytosolic pS2 protein content in gastric cancer. Int. J. Biol. Markers 2001, 16, 37-44. [CrossRef]

49. Doster, A.R.; Yhee, J.Y.; Kim, J.H.; Im, K.S.; Sur, J.H. CDX-2 and HER-3 expression in canine gastric and colorectal adenocarcinomas. J. Comp. Pathol. 2011, 145, 12-19. [CrossRef] 